Article

\title{
Graphene/PVDF Composites for Ni-rich Oxide Cathodes toward High-Energy Density Li-ion Batteries
}

\author{
Chang Won Park ${ }^{1,2}$, Jung-Hun Lee ${ }^{3}$, Jae Kwon Seo ${ }^{3}$, Weerawat To A Ran ${ }^{3}{ }^{(D}$, Dongmok Whang ${ }^{1,3}$, \\ Soo Min Hwang ${ }^{3, *(D)}$ and Young-Jun Kim ${ }^{3,4, *(D)}$ \\ 1 School of Advanced Materials Science and Engineering, Sungkyunkwan University, Suwon 16419, Korea; \\ ason22@naver.com (C.W.P.); dwhang@skku.edu (D.W.) \\ 2 AEB Cell Development Team, Samsung SDI Co., LTD, Yongin 17084, Korea \\ 3 SKKU Advanced Institute of Nano Technology (SAINT), Sungkyunkwan University, Suwon 16419, Korea; \\ lee40003@naver.com (J.-H.L.); kwon4014@naver.com (J.K.S.); weerawat@skku.edu (W.T.A.R.) \\ 4 Department of Nano Engineering, Sungkyunkwan University, Suwon 16419, Korea \\ * Correspondence: smhwang@skku.edu (S.M.H.); yjkim68@skku.edu (Y.-J.K.)
}

Citation: Park, C.W.; Lee, J.-H.; Seo, J.K.; Ran, W.T.A; Whang, D.; Hwang, S.M.; Kim, Y.-J. Graphene/PVDF Composites for Ni-rich Oxide Cathodes toward High-Energy Density Li-ion Batteries. Materials 2021, 14, 2271. https://doi.org/ $10.3390 /$ ma14092271

Academic Editor: Alvaro Caballero

Received: 24 March 2021

Accepted: 20 April 2021

Published: 27 April 2021

Publisher's Note: MDPI stays neutral with regard to jurisdictional claims in published maps and institutional affiliations.

Copyright: (c) 2021 by the authors. Licensee MDPI, Basel, Switzerland. This article is an open access article distributed under the terms and conditions of the Creative Commons Attribution (CC BY) license (https:// creativecommons.org/licenses/by/ $4.0 /)$.

\begin{abstract}
Li-ion batteries (LIBs) employ porous, composite-type electrodes, where few weight percentages of carbonaceous conducting agents and polymeric binders are required to bestow electrodes with electrical conductivity and mechanical robustness. However, the use of such inactive materials has limited enhancements of battery performance in terms of energy density and safety. In this study, we introduced graphene/polyvinylidene fluoride (Gr/PVdF) composites in Ni-rich oxide cathodes for LIBs, replacing conventional conducting agents, carbon black (CB) nanoparticles. By using $\mathrm{Gr} / \mathrm{PVdF}$ suspensions, we fabricated highly dense $\mathrm{LiNi}_{0.85} \mathrm{Co}_{0.15} \mathrm{Al}_{0.05} \mathrm{O}_{2}$ (NCA) cathodes having a uniform distribution of conductive Gr sheets without CB nanoparticles, which was confirmed by scanning spreading resistance microscopy mode using atomic force microscopy. At a high content of $99 \mathrm{wt}$ \% NCA, good cycling stability was shown with significantly improved areal capacity $\left(Q_{\text {areal }}\right)$ and volumetric capacity $\left(Q_{\mathrm{vol}}\right)$, relative to the $C B / P V d F-c o n t a i n i n g ~ N C A$ electrode with a commercial-level of electrode parameters. The NCA electrodes using 1 wt.\% Gr/PVdF (0.9:0.1) delivered a high $Q_{\text {areal }}$ of $\sim 3.7 \mathrm{mAh} \mathrm{cm}^{-2}(\sim 19 \%$ increment $)$ and a high $\mathrm{Q}_{\mathrm{vol}}$ of $\sim 774 \mathrm{mAh} \mathrm{cm}^{-3}$ ( $\sim 18 \%$ increment) at a current rate of $0.2 \mathrm{C}$, as compared to the conventional NCA electrode. Our results suggest a viable strategy for superseding conventional conducting agents (CB) and improving the electrochemical performance of Ni-rich cathodes for advanced LIBs.
\end{abstract}

Keywords: lithium-ion batteries; Ni-rich cathodes; graphene; PVDF; electrode density; scanning probe microscopy

\section{Introduction}

In an attempt to meet the global energy demand while maintaining sustainable development of society, rechargeable batteries have been considered to be effective solutions for renewable energy [1,2]. Lithium-ion batteries (LIBs) have been used as major power sources for a variety of applications, including portable electronics and electric vehicles, since having been devised in the 1990s [3-7]. Lower energy cost LIBs are desirable (i.e., $<\$ 125 \mathrm{kWh}^{-1}$ for pack cost for electric vehicles) for providing a longer lifespan at an affordable cost $[1,8]$. Accordingly, most research has focused on the development of electrode materials and the electrode engineering via tuning the electrode parameters toward cycling-stable LIBs with high-energy density [4-9].

LIB electrodes are composed of a porous, composite-type film coated on a current collector foil, where the film contains active materials, carbonaceous conducting agents, and polymeric binders. Due to their low electrical conductivities, typical cathodes for LIBs require few percentages of nanoscale conductive additives, such as carbon blacks (CBs). However, employing CB nanoparticles in electrodes causes intrinsic challenges in 
electrode manufacturing processes, such as slurry formulation and coating/drying steps, due to their agglomeration behavior $[10,11]$. In addition, the low tap density of CB restricts an improvement of volumetric capacity (energy density) of electrodes. In practice, the slurry preparation step is decisive in a subsequent slurry coating process and the resulting electrochemical performance of electrodes [10]. Many studies on slurry processing have been conducted to improve rheological behavior and resulting electrode performance by modifying the methods and sequences of constituent mixing [10,12-14]. Nevertheless, the uniform dispersion of $C B$ nanoparticles within a slurry and hence, their effective distribution in electrodes for ensuring the conductive pathways still remain challenging, even with smaller CB contents.

In this study, we used $\mathrm{Gr}$ nanosheets as a conducting agent in a Ni-rich oxide cathode, $\mathrm{LiNi}_{0.85} \mathrm{Co}_{0.15} \mathrm{Al}_{0.05} \mathrm{O}_{2}$ (NCA), replacing conventional CB nanoparticles for LIBs. By simply mixing an electrochemically exfoliated $\mathrm{Gr}$ dispersion and a polyvinylidene fluoride (PVdF) binder solution, we fabricated uniform $\mathrm{Gr} / \mathrm{PVdF}$ suspensions with controlled $\mathrm{Gr}$ contents; this enabled uniform distribution of the Gr nanosheets within NCA electrodes due to the intimate interactions of the functional groups of $\mathrm{Gr}$ and the electronegative fluorine in PVdF. Surface probe microscopy on a cross section of the electrodes was conducted to differentiate the microstructure and intraparticle resistances. Using $1 \mathrm{wt} . \% \mathrm{Gr} / \mathrm{PVdF}$ suspension (Gr:PVdF = 0.9:0.1 in wt.\%) without a conventional $C B$, we achieved highly dense NCA cathodes ( $99 \mathrm{wt} . \%$ NCA; electrode density $(\rho) \sim 3.8 \mathrm{~g} \mathrm{~cm}^{-3}$ ) that showed good cycling stability and higher areal capacity $\left(\mathrm{Q}_{\text {areal }}\right)$ and volumetric capacity $\left(\mathrm{Q}_{\mathrm{vol}}\right)$ than those of a counterpart with a commercial-level of electrode parameters (96 wt.\% NCA; $\rho \sim 3.3 \mathrm{~g} \mathrm{~cm}^{-3}$ ) at a current rate of $0.2 \mathrm{C}$.

\section{Materials and Methods}

\subsection{Preparation of $G r / P V d F$ Suspensions}

Gr nanosheets were prepared using an electrochemical exfoliation method. As the electrolyte, an aqueous solution containing $0.5 \mathrm{M}$ ammonium sulfate $\left(\left(\mathrm{NH}_{4}\right)_{2} \mathrm{~S}_{2} \mathrm{O}_{8}\right)$ was used, where two graphite foil electrodes were immersed in parallel at a fixed distance of $10 \mathrm{~mm}$. When applying a DC voltage $(+10 \mathrm{~V})$ between the two graphite electrodes for about $10 \mathrm{~min}$, a positively charged electrode was gradually exfoliated into Gr nanosheets, which was then collected through vacuum filtration, followed by washing with deionized water and ethanol. Gr/PVdF suspensions with various Gr contents (10-90 wt.\%) were prepared in the following two steps. First, the Gr dispersion and PVdF (Solef ${ }^{\circledR}$ 6020, Solvay, Brussels, Belgium) solution were prepared at concentrations of $2 \mathrm{wt} . \%$ and $10 \mathrm{wt} . \%$ in N-methyl-2pyrrolidone (NMP), respectively. The two separate solutions were then prepared with a vortex mixer to form $\mathrm{Gr} / \mathrm{PVdF}$ suspensions at different $\mathrm{Gr}$ contents (10-90 wt.\%).

\subsection{Electrochemical Testing}

The cathode slurries were prepared by mixing $99 \mathrm{wt} . \%$ NCA powder (Samsung SDI, Yongin, Korea) and $1 \mathrm{wt} . \% \mathrm{Gr} / \mathrm{PVdF}$ suspensions, where the Gr content was varied from 0.1 to $0.9 \mathrm{wt} . \%$. The as-prepared slurries were cast on a $20 \mu \mathrm{m}$-thick $\mathrm{Al}$ foil using a doctor blade method and dried in a convection oven at $80^{\circ} \mathrm{C}$ for $2 \mathrm{~h}$, followed by vacuum drying at $120^{\circ} \mathrm{C}$ overnight. For comparison, NCA electrodes with commercial-level electrode parameters of NCA:CB (Super $\mathrm{P}^{\circledR}$, Imerys Graphite \& Carbon, Bironico, Switzerland):PVdF $=96: 2: 2$ were prepared. The $\rho$ was set as $3.8( \pm 0.1) \mathrm{g} \mathrm{cm}^{-3}$ and $3.3( \pm 0.1) \mathrm{g} \mathrm{cm}^{-3}$ for Gr-containing electrodes and CB-containing electrodes, respectively. The mass loading was set as $\sim 16 \mathrm{mg} \mathrm{cm}^{-2}$ and it was increased to $\sim 19 \mathrm{mg} \mathrm{cm}^{-2}$, to fabricate thicker electrodes. The electrodes were punched into discs with a diameter of $12 \mathrm{~mm}$. Coin-type 2032 cells were assembled for electrochemical testing in an Ar filled glove box, with a lithium metal counter-electrode (16 $\Phi$ ) and polypropylene separator (Celgard 2400, Celgard, Charlotte, $\mathrm{NC}$, USA). $\mathrm{LiPF}_{6}(1 \mathrm{M})$ in a solvent mixture of ethylene carbonate, ethyl methyl carbonate, and dimethyl carbonate at a volume ratio of $2: 4: 4$ with $1.5 \%$ vinylene carbonate additive was used as the electrolyte. 
Electrochemical properties were measured using a WBCS3000L battery cycler (WonATech, Seoul, Korea). The formation process was conducted at $0.2 \mathrm{C}\left(1 \mathrm{C}=200 \mathrm{mAh} \mathrm{g}^{-1}\right)$ in the voltage range of $2.75-4.3 \mathrm{~V}$ vs. $\mathrm{Li}^{+} / \mathrm{Li}$ for two cycles with a CC-CV charge mode using a $0.05 \mathrm{C}$ cut-off. The discharge rate capability was measured at various current rates of 0.2-10 C after charging at $0.2 \mathrm{C}$ with a CC-CV protocol using a $0.05 \mathrm{C}$ cut-off. The cycle performance was evaluated at 30 and $60^{\circ} \mathrm{C}$ in the voltage range of $2.75-4.3 \mathrm{~V}$ or $2.75-4.5 \mathrm{~V}$ vs. $\mathrm{Li}^{+} / \mathrm{Li}$ at a current rate of $0.5 \mathrm{C}$ with a CC-CV charging protocol using a $0.05 \mathrm{C}$ cut-off after two cycles of the formation process. Electrochemical impedance spectroscopy (EIS) was carried out using a biologic VSP-100 instrument in the frequency range of $1 \mathrm{MHz}$ to $10 \mathrm{mHz}$ with a voltage perturbation of $10 \mathrm{mV}$. The internal pressure change was monitored using a home-made gas cell system containing a cathode charged to $4.5 \mathrm{~V} \mathrm{vs.} \mathrm{Li}^{+} / \mathrm{Li}$ and $10 \mathrm{~mL}$ of a fresh electrolyte at $60^{\circ} \mathrm{C}$ for $24 \mathrm{~h}$ in an Ar atmosphere.

\subsection{Characterizations}

The microstructure and Gr distribution were observed using field-emission scanning electron microscopy (SEM, JSM-7600F, JEOL Ltd., Tokyo, Japan). The samples were crosssectioned using a cross-section polisher (SM-09010, JEOL Ltd., Tokyo, Japan). The in-plane resistance of NCA electrodes was measured using an electrode resistance measurement system (RM2610, Hioki, Nagano, Japan). The electrical resistance distribution inside the cross-sectioned electrodes was measured in scanning spreading resistance microscopy (SSRM) mode using atomic force microscopy (AFM, NX-10, Park systems, Suwon, Korea) equipped with a diamond-coated probe (CDT-NCHR, NANOSENSORSTM, Neuchatel, Switzerland) with a nominal force constant of $80 \mathrm{~N} \mathrm{~m}^{-1}$ over a scan area of $10 \times 10 \mu \mathrm{m}^{2}$. By applying appropriate bias voltages $(\sim 1.5 \mathrm{~V})$, the current passing through samples (between the tip and sample base, Al current collector) was recorded using a logarithmic current amplifier in SSRM mode.

\section{Results and Discussion}

We prepared Gr dispersions by an electrochemical exfoliation method with commercially available graphite foils [15-17]. By applying a DC voltage (+10 V), a graphite foil was exfoliated into Gr sheets in an aqueous ammonium persulfate solution $(0.5 \mathrm{M})$, due to the evolution of gases, such as $\mathrm{SO}_{2}$ and $\mathrm{O}_{2}$. The as-exfoliated $\mathrm{Gr}$ sheets were then collected by vacuum filtration and washing processes, followed by dispersion in a NMP solvent, as schematically depicted in Figure 1a. The exfoliated Gr sheets have lateral sizes of 0.1-2 $\mu \mathrm{m}$ and an average thickness of $4.6 \mathrm{~nm}$ (refer to Figure S1). The Gr surface/edges appeared to be partially oxygen-functionalized $(\mathrm{C}-\mathrm{OH} / \mathrm{C}-\mathrm{O} / \mathrm{C}=\mathrm{O})$ due to the oxidation of graphite by $\mathrm{OH}^{-}$ions during the electrochemical process on the basis of XPS C 1s spectra (Figure S2) $[16,17]$. We performed confocal Raman mapping on the exfoliated Gr sheets, which showed the high-intensity $G$ peak and 2D peak at $\sim 1580$ and $\sim 2700 \mathrm{~cm}^{-1}$, respectively, with an intensity ratio of $\mathrm{D}$ to $\mathrm{G}\left(\mathrm{I}_{\mathrm{D}} / \mathrm{I}_{\mathrm{G}}\right)$ of $\sim 0.3$ (Figure $\mathrm{S} 3$ ), which is much lower than that of chemically or thermally reduced graphene oxides $\left(\mathrm{I}_{\mathrm{D}} / \mathrm{I}_{\mathrm{G}}=1.2-1.5\right)[15,18,19]$. 
a
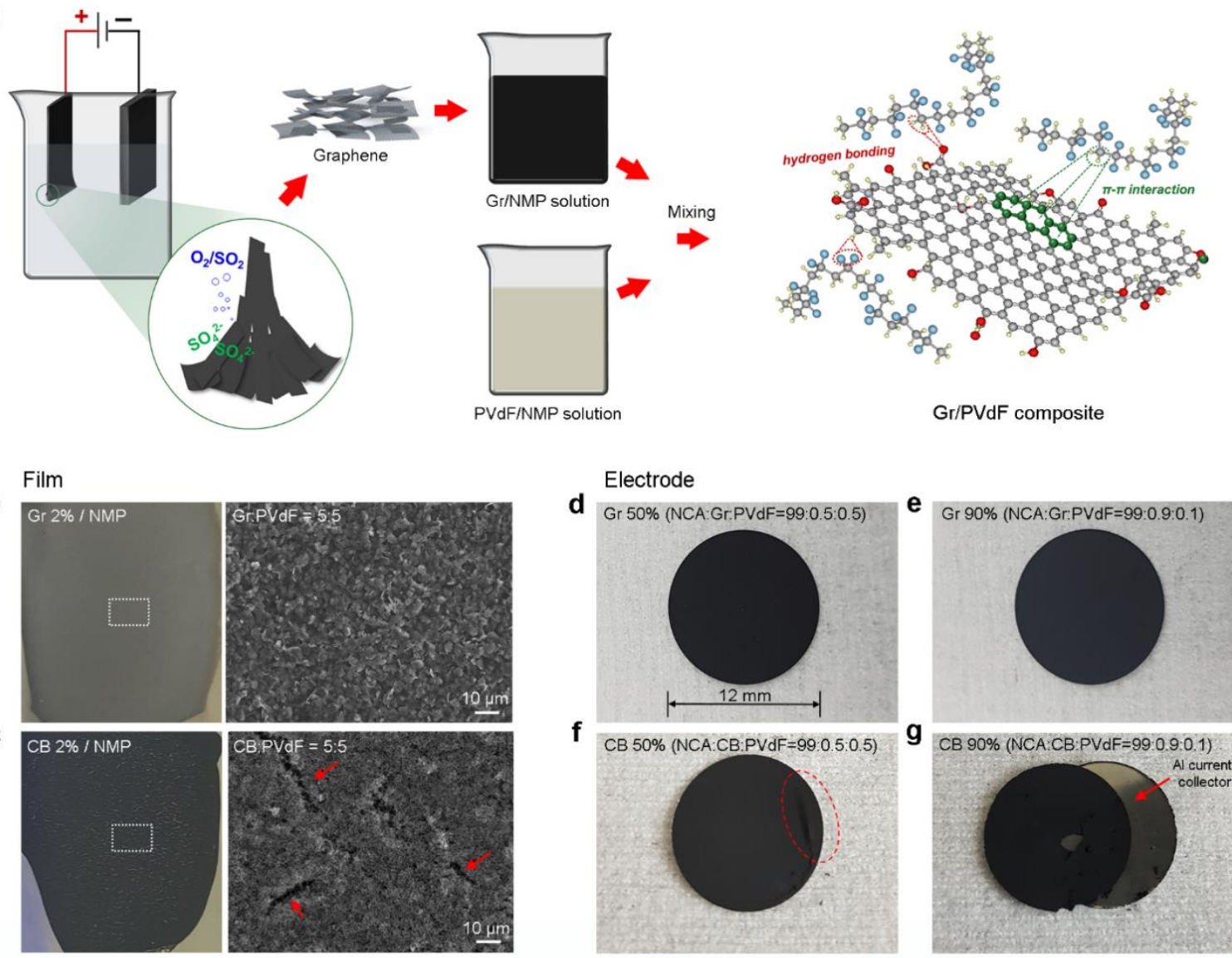

f
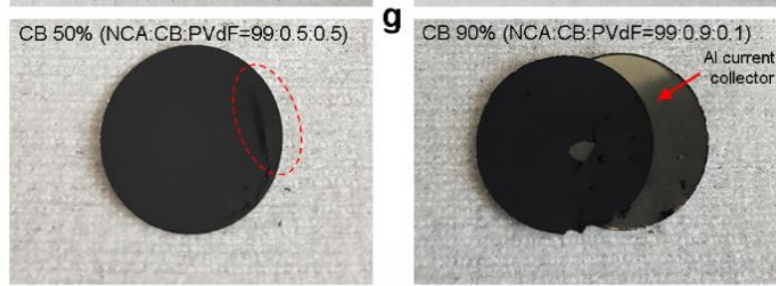

Figure 1. (a) Schematic of the preparation steps of Gr/PVdF suspensions and the bonding configurations between Gr and $\mathrm{PVdF}$, where red, grey, ivory, and blue spheres indicate oxygen, carbon, hydrogen, and fluorine, respectively; digital images and SEM images of (b) Gr/PVdF and (c) CB/PVdF films, where the red arrows indicate microcracks on the film surface; and digital images of NCA electrodes with (d) $0.5 \mathrm{wt} . \%$ and (e) $0.9 \mathrm{wt} . \%$ Gr and (f) $0.5 \mathrm{wt} . \%$ and (g) $0.9 \mathrm{wt} . \%$ CB. The red dotted circle and red arrow indicate delamination from the Al current collector.

$\mathrm{Gr} / \mathrm{PVdF}$ suspensions were fabricated by simply mixing the $\mathrm{Gr}$ dispersion $(2 \mathrm{wt} . \% \mathrm{Gr})$ and PVdF solution (10 wt.\% in NMP) at different Gr contents (10-90 wt.\%), speculating that two types of interactions between the Gr sheets and PVdF occur:-(i) hydrogen bonding between the oxygen functional groups $(-\mathrm{O}-\mathrm{C} /-\mathrm{OH})$ on $\mathrm{Gr}$ and $-\mathrm{CF}_{2} /-\mathrm{CH}_{2}$ dipoles in $\mathrm{PVdF}$ and (ii) $\pi-\pi$ interactions between the delocalized $\pi$ electrons in $\mathrm{Gr}$ and $-\mathrm{CH}_{2}$ dipoles in PVdF-(see the right side of Figure 1a) [20-25]. A Gr/PVdF suspension (50:50 in wt.\%) was cast on an $\mathrm{Al}$ foil and the film microstructure was compared to that of the film coated with a $\mathrm{CB} / \mathrm{PVdF}$ suspension (50:50 in wt.\%). As shown in Figure 1b,c, the Gr/PVdF film appeared to be highly homogeneous without noticeable protrusions and the plan-view SEM image showed uniform microstructure (Figure $1 b$ ). On the other hand, local protrusions and microcracks were found on the surface of the $\mathrm{CB} / \mathrm{PVdF}$ film, as indicated by red arrows in Figure 1c. This difference in the microstructure between the two different type films could stem from the specific interactions between the Gr sheets and PVdF and the intrinsic agglomeration of CB in NMP (refer to Figure S4). The agglomeration of CB can cause intrinsic issues in slurry formation and coating/drying processes for electrode fabrication.

Typically, inactive components, such as CB and PVdF binder, have been used to build Ni-rich oxide cathodes; however, they should be minimized to enhance the energy density (volumetric capacity) of electrodes [26,27]. We fabricated electrodes having a high NCA content (99 wt.\%) using Gr/PVdF and CB/PVdF suspensions (Figure 1d-g). The NCA electrodes composed of $\mathrm{Gr} / \mathrm{PVdF}$ were robust without noticeable delamination from the $\mathrm{Al}$ foil current collector, even for the electrode containing a low PVdF content (0.1 wt.\%; 
Figure 1e). By contrast, the NCA electrodes using the CB/PVdF were easily detached after electrode punching: the electrode containing $0.1 \mathrm{wt} . \%$ PVdF binder was completely delaminated from the current collector (Figure 1g).

We assessed rate capability of NCA electrodes that were fabricated using Gr/PVdF suspensions with different Gr contents ( $x$ in NCA:Gr:PVdF $=99: x: 1-x)$ and compared a NCA electrode with a commercial-level electrode setting with NCA:CB:PVdF $=96: 2: 2$ and $\rho \sim 3.3 \mathrm{~g} \mathrm{~cm}^{-3}$, which is hereafter denoted as the Ref. electrode. The discharge rate capability of the NCA electrodes measured at $0.2-10 \mathrm{C}$ are shown in Figure 2a and the corresponding voltage profiles measured in the voltage range of $2.75-4.3 \mathrm{~V} \mathrm{vs} . \mathrm{Li}^{+} / \mathrm{Li}$ are shown in Figure S5. The NCA electrode containing $0.9 \mathrm{wt} . \%$ Gr exhibited good rate performance, comparable to that of the Ref. electrode: the two electrodes had $\sim 200$ and $\sim 183 \mathrm{mAh} \mathrm{g}^{-1}$ at $0.2 \mathrm{C}$ and $2 \mathrm{C}$, respectively. The NCA electrodes with less $\mathrm{Gr}$ contents $(0.5$ and $0.7 \mathrm{wt} . \%$ ) showed slightly inferior performance, which could be attributed to the low electrical conductivities. These results were corroborated by in-plane conductivity and EIS measurements. As shown in Figure 2b, only the NCA electrode containing 0.9 wt. $\%$ Gr exhibited a comparable electrical conductivity with that of the Ref. electrode, whereas the others had low conductivities. In addition, we compared Nyquist plots of the NCA electrodes in configurations of a symmetric cell (NCA I NCA) and an asymmetric cell ( $\mathrm{Li}$ I NCA), as depicted in Figure S6. The data for symmetric cells before the formation process (Figure S6a) revealed that the contact resistance between NCA particles and current collector and the interparticle resistance within electrodes was decreased with increasing Gr content [28,29]: the Nyquist plot of $0.9 \mathrm{wt} . \%$ Gr-NCA electrode was similar to that of the Ref. electrode. Similarly, for asymmetric cells after formation (Figure S6b), $0.9 \mathrm{wt} . \%$ Gr-NCA electrode and Ref. electrode had almost similar trends in the Nyquist plots, two depressed arcs at high frequencies and a straight line inclined at a constant angle to the real axis at low frequencies [30].
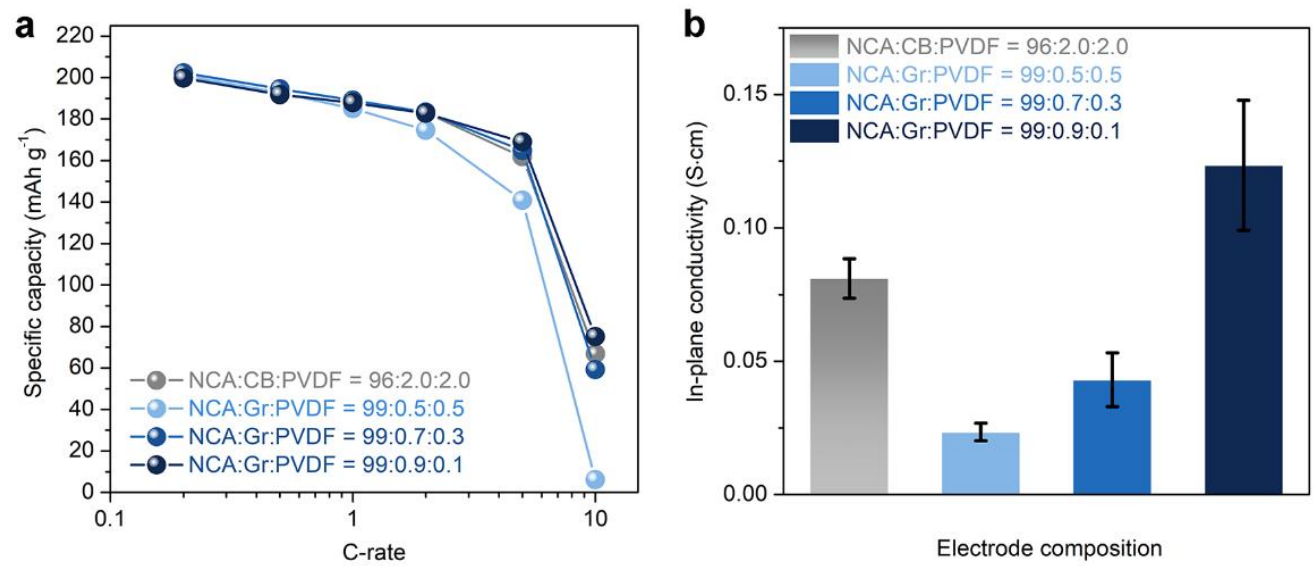

Figure 2. (a) Rate capability at $0.2-10 \mathrm{C}$ and (b) in-plane conductivity of NCA electrodes with different electrode compositions. The $\rho$ was set as $\sim 3.8 \mathrm{~g} \mathrm{~cm}^{-3}$ and $\sim 3.3( \pm 0.1) \mathrm{g} \mathrm{cm}^{-3}$ for Gr-containing electrodes and CB-containing electrodes, respectively.

Next, we evaluated the cycle performance of NCA electrodes with different electrode compositions, measured in the voltage ranges of $2.75-4.3 \mathrm{~V}$ or $2.75-4.5 \mathrm{~V} \mathrm{vs}$. $\mathrm{Li}^{+} / \mathrm{Li}$ at a current rate of $0.5 \mathrm{C}$ and temperatures of $30^{\circ} \mathrm{C}$ and $60^{\circ} \mathrm{C}$. As shown in Figure $3 \mathrm{a}, \mathrm{b}$, the NCA electrode with $0.9 \mathrm{wt} . \%$ Gr exhibited a similar capacity retention to the Ref. electrode at $30^{\circ} \mathrm{C}$ and $60^{\circ} \mathrm{C}$, respectively. With the decreasing $\mathrm{Gr}$ content, the capacity decay was severe. Under the operation at high-voltage cut-off condition $\left(2.75-4.5 \mathrm{~V} \mathrm{vs.} \mathrm{Li}^{+} / \mathrm{Li}\right)$ and $30{ }^{\circ} \mathrm{C}$, both the $0.9 \mathrm{wt} . \% \mathrm{Gr}-\mathrm{NCA}$ electrode and the Ref. electrode had similar behaviors during 100 cycles (Figure 3c). These results confirm that even with a high NCA content (99 wt.\%), but low contents of inactive components (total $1 \mathrm{wt} . \%$ ), the NCA electrodes show excellent cycling stability, comparable to the Ref. electrode containing high contents 
of $\mathrm{CB} / \mathrm{PVdF}$ (total $4 \mathrm{wt} . \%$ ). Note that the Gr-NCA electrodes had a considerably higher $\rho\left(\sim 3.8 \mathrm{~g} \mathrm{~cm}^{-3}\right)$ than that of the Ref. electrode $\left(\rho \sim 3.3 \mathrm{~g} \mathrm{~cm}^{-3}\right)$, featuring dense electrode architectures. By considering the electrode volume, we replotted the $\mathrm{Q}_{\mathrm{vol}}$ retention data in Figure $3 \mathrm{~d}-\mathrm{f}$. The NCA electrode with $0.9 \mathrm{wt} . \% \mathrm{Gr}$ exhibited a considerably large $\mathrm{Q}_{\mathrm{vol}}$, compared to that of the Ref. electrode. For example, at $30{ }^{\circ} \mathrm{C}$ (Figure $3 \mathrm{~d}$ ), the $0.9 \mathrm{wt} . \%$ Gr-NCA electrode had a $\mathrm{Q}_{\mathrm{vol}}$ of $\sim 790 \mathrm{mAh} \mathrm{cm}^{-3}$ at the 1 st cycle and delivered a $\mathrm{Q}_{\mathrm{vol}}$ of $\sim 580 \mathrm{mAh} \mathrm{cm}^{-3}$ at the 100th cycle ( 73\% retention), whereas the Ref. electrode had a $\mathrm{Q}_{\mathrm{vol}}$ of $\sim 610 \mathrm{mAh} \mathrm{cm}^{-3}$ and $\sim 460 \mathrm{mAh} \mathrm{cm}^{-3}$ at 1st and 100th cycles, respectively, with capacity retention of $\sim 75 \%$.
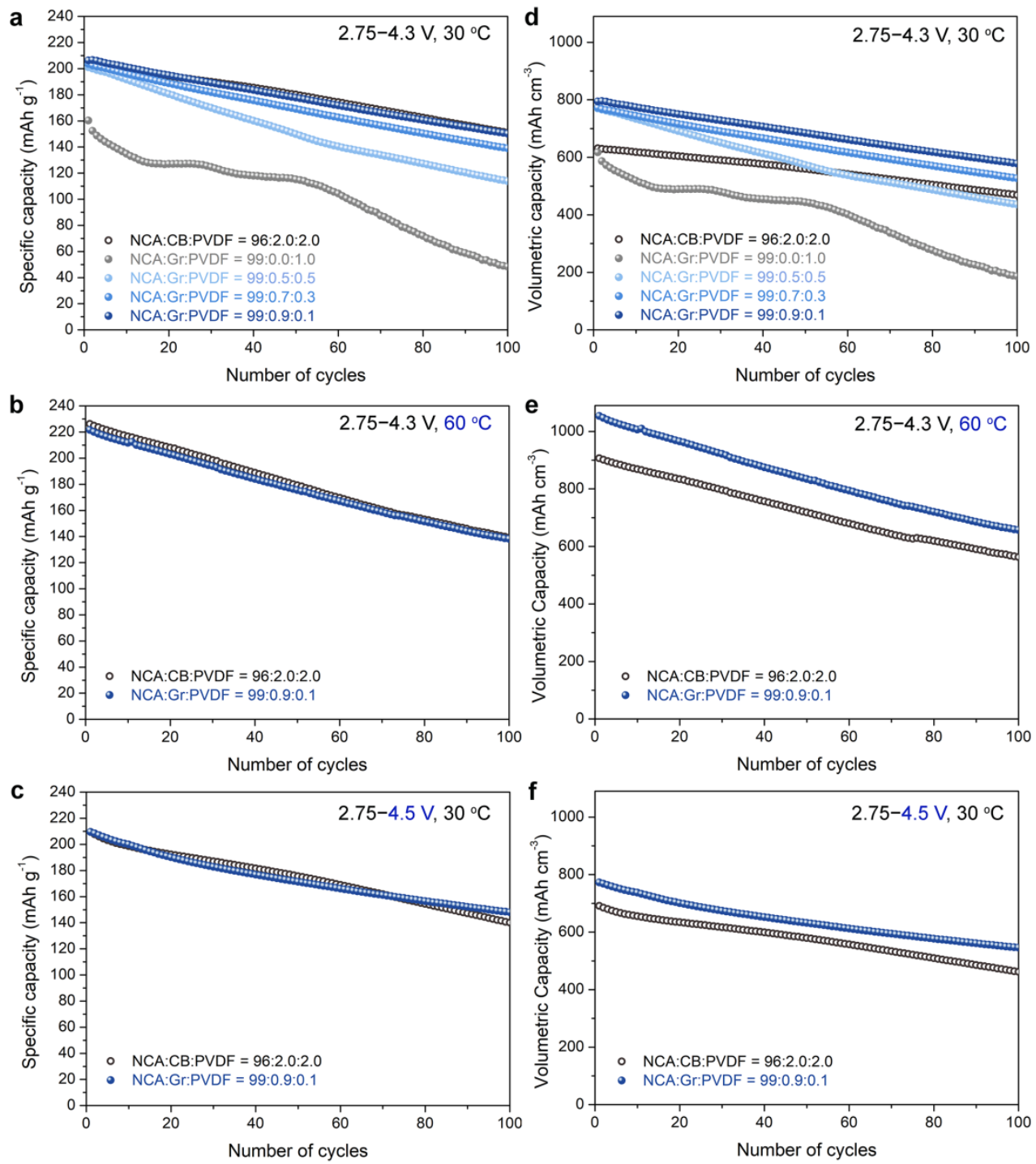

Figure 3. (a-c) Specific capacity retention and (d-f) volumetric capacity retention of NCA electrodes with different electrode compositions at current rate of $0.5 \mathrm{C}$, measured in the voltage range of $(\mathbf{a}, \mathbf{d})$ 2.75-4.3 V at $30^{\circ} \mathrm{C},(\mathbf{b}, \mathbf{e}) 2.75-4.3 \mathrm{~V}$ at $60^{\circ} \mathrm{C}$, and $(\mathbf{c}, \mathbf{f}) 2.75-4.3 \mathrm{~V}$ at $30^{\circ} \mathrm{C}$.

To differentiate the microstructure and components distribution for NCA electrodes with different compositions ( $1 \mathrm{wt} . \% \mathrm{Gr} / \mathrm{PVdF}$ vs. $4 \mathrm{wt} . \% \mathrm{CB} / \mathrm{PVdF}$ ), we performed CPSEM observation for 0.9 wt.\% Gr-NCA and Ref. electrodes. As shown in Figure $4 \mathrm{a}_{1}, \mathrm{~b}_{1}$, a distinct difference in the electrode thicknesses between the $0.9 \mathrm{wt} . \%$ Gr-NCA electrode and Ref. electrode was observed due to their different $\rho$. The Gr sheets were uniformly distributed within the Gr-NCA electrode, overall (Figure $4 b_{2}-b_{4}$ ). On the other hand, the Ref. electrode showed local agglomeration of CB nanoparticles between the NCA particles 
(Figure $4 \mathrm{a}_{2}-\mathrm{a}_{4}$ ). It is noteworthy that the $0.9 \mathrm{wt}$ \% Gr-NCA electrode had no notable micro-cracks, even after a high-pressure calendaring process for high electrode density $\left(3.8 \mathrm{~g} \mathrm{~cm}^{-3}\right)$. We further conducted SSRM measurements combined with AFM on the cross section for the $0.9 \mathrm{wt}$.\% Gr-NCA and Ref. electrodes, to visualize spatial heterogeneity of the resistance within NCA particles (see Figure 4c,d). Comparison between the resistance mapping images revealed that the Gr-NCA electrode had relatively uniform distributions of the intraparticle resistance, relative to those of the Ref. electrode. This result indicates that the use of Gr/PVdF suspension affords the uniform distribution of the conducting agent, Gr and hence, effective conducting pathways within NCA electrodes, even with a significantly small Gr amount (0.9 wt.\%).
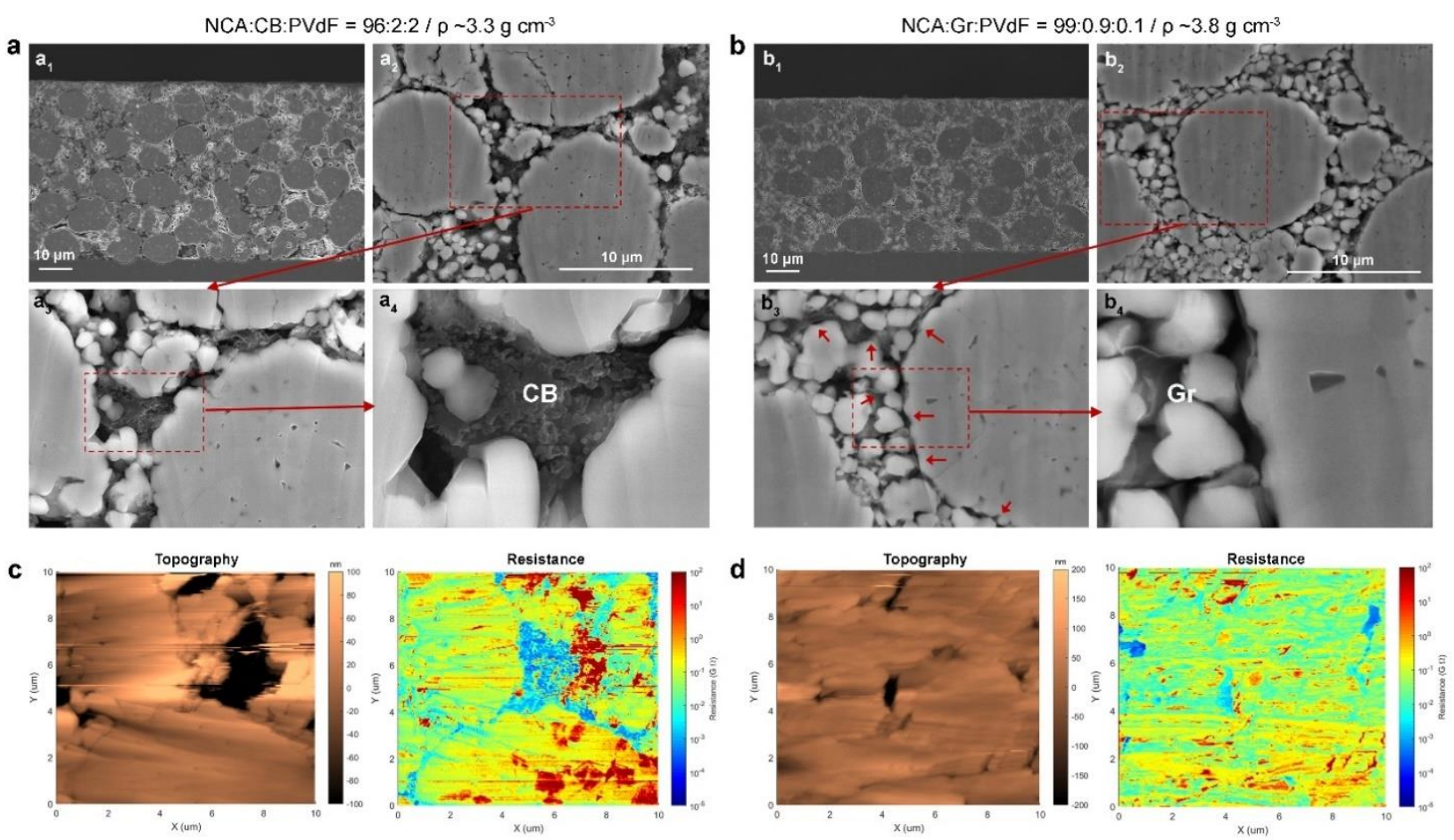

Figure 4. ( $\left.\mathbf{a}_{1}-\mathbf{a}_{4}, \mathbf{b}_{1}-\mathbf{b}_{4}\right)$ Cross-sectional SEM images and (c,d) AFM and SSRM images of NCA electrodes with (a,c) $\mathrm{CB} / \mathrm{PVdF}$ and $(\mathbf{b}, \mathbf{d}) \mathrm{Gr} / \mathrm{PVdF}$. The red arrows in $\mathrm{b}_{3}$ indicate $\mathrm{Gr}$ sheets between the NCA particles.

Ni-rich oxide cathodes have been reported to cause safety issues due to structural instability arising from the phase transition during repeated cycles, accompanied by the evolution of $\mathrm{O}_{2}$ and $\mathrm{CO}_{2}$ gases [31,32]. This behavior is accelerated under battery operation with overcharging $\left(>4.3 \mathrm{~V}\right.$ vs. $\left.\mathrm{Li}^{+} / \mathrm{Li}\right)$ and/or at elevated temperatures in the charged state. In addition, inactive materials such as $\mathrm{CB}$ and $\mathrm{PVdF}$ can release gaseous $\mathrm{CO}_{2}$ through oxidation reactions with reactive oxygen species generated from charged NCA particles [33]. Such gaseous byproducts could induce severe thermal runaway by highly exothermic reaction with flammable electrolytes. We monitored the internal pressure change with respect to testing time using a home-made gas cell system, which contained a NCA electrode fully charged to $4.5 \mathrm{~V} \mathrm{vs}$. $\mathrm{Li}^{+} / \mathrm{Li}$ and $10 \mathrm{~mL}$ of a fresh electrolyte, at $60{ }^{\circ} \mathrm{C}$ in Ar atmosphere (refer to the inset of Figure 5). An empty cell and a cell containing only electrolyte were also examined as references. As shown in Figure 5, as the testing proceeded, the internal pressure monotonically increased for all the cells. The NCA electrode containing Gr/PVdF exhibited a relatively small increase of the pressure, as compared to that of the Ref. electrode, which appeared to be a result of the use of less contents of inactive materials, confirming the efficacy of Gr/PVdF suspension. 


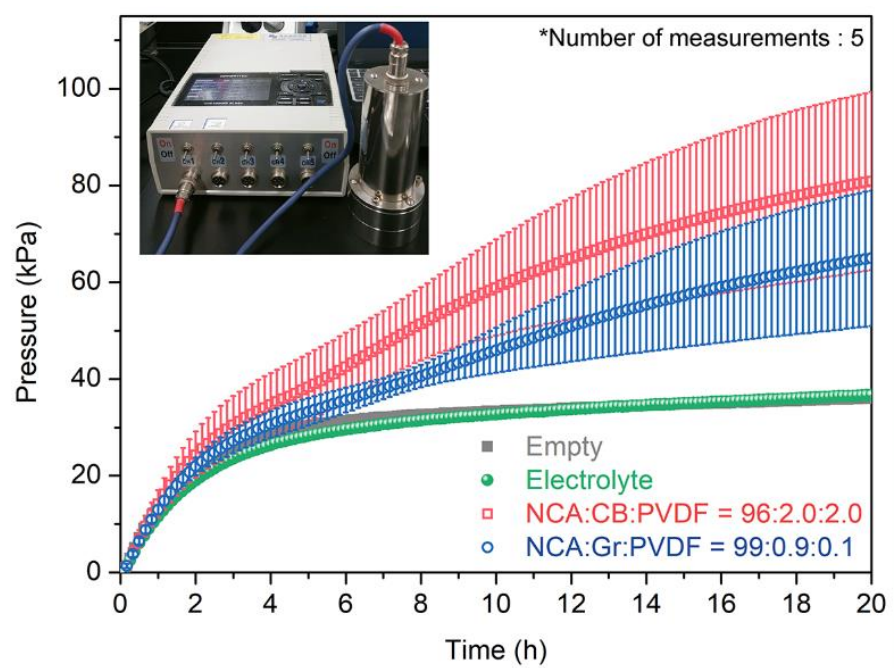

Figure 5. Internal pressure changes of in-situ gas cells, which contained NCA electrodes with CB/PVdF and Gr/PVdF (number of measurements: 5 times). Graphs for an empty cell and a cell containing only electrolyte as references are also shown.

Lastly, we evaluated discharge $Q_{\text {areal }}$ and $Q_{\text {vol }}$ of NCA electrodes containing $1 \mathrm{wt} . \%$ $\mathrm{Gr} / \mathrm{PVdF}$. We fabricated three types of Gr-NCA electrodes (Gr-A, Gr-B, and Gr-C) with different electrode parameters, such as mass loading ( $\mathrm{m}_{\text {areal }} ; 16 \mathrm{mg} \mathrm{cm}^{-2}$ vs. $19 \mathrm{mg} \mathrm{cm}^{-2}$ ) and electrode density, $\rho$ ( 3.3 vs. $3.8 \mathrm{~g} \mathrm{~cm}^{-3}$ ), to compare with the Ref. electrode containing 4 wt.\% CB/PVdF (mareal; $16 \mathrm{mg} \mathrm{cm}^{-2} ; \rho \sim 3.3 \mathrm{~g} \mathrm{~cm}^{-3}$ ). Figure $6 \mathrm{a}-\mathrm{d}$ show the crosssectional SEM images of the four electrodes with different electrode parameters. For the Ref. electrode (Figure 6a), the presence of intraparticle microcracks was prominent. On the other hand, overall, the microstructures of Gr-NCA electrodes with a high $\rho$ of $3.8 \mathrm{~g} \mathrm{~cm}^{-3}$ (Gr-A and Gr-B; Figure 6b,c) and Gr-NCA electrode with the same $\rho\left(3.3 \mathrm{~g} \mathrm{~cm}^{-3}\right.$; Gr-C; Figure $6 \mathrm{~d}$ ) were intact after the calendaring process. These results confirm that the lowdensity CB-containing Ref. electrode with conventional electrode parameters have a limited $\rho\left(\leq 3.3 \mathrm{~g} \mathrm{~cm}^{-3}\right)$ and hence, a $Q_{\mathrm{vol}}$ limit $[34,35]$. The $Q_{\text {areal }}$ and $Q_{\mathrm{vol}}$ of NCA electrodes with respect to areal current are depicted in Figure 6e,f, respectively. All of the electrodes showed monotonic capacity decreases with increasing areal current. The Gr-A electrode (red symbols) exhibited similar trend in the $Q_{\text {areal }}$ decay with the Ref. electrode (black symbols). However, the Gr-A electrode delivered a considerably large $\mathrm{Q}_{\mathrm{vol}}$ of $\sim 768 \mathrm{mAh}$ $\mathrm{cm}^{-3}\left(\sim 17 \%\right.$ increase) at $0.2 \mathrm{C}$, compared to that of the Ref. electrode $\left(\mathrm{Q}_{\mathrm{vol}}\right.$ of $\sim 655 \mathrm{mAh}$ $\mathrm{cm}^{-3}$ ). It should be noted that for Gr-B electrode (blue symbols), both the $\mathrm{Q}_{\text {areal }}$ and $\mathrm{Q}_{\mathrm{vol}}$ were larger than those of Ref. electrode at $0.2 \mathrm{C}-2 \mathrm{C}$ : the $\mathrm{Q}_{\mathrm{areal}}$ and $\mathrm{Q}_{\mathrm{vol}}$ of $\mathrm{Gr}-\mathrm{B}$ were $\sim 3.7 \mathrm{mAh} \mathrm{cm}^{-2}$ and $\sim 774 \mathrm{mAh} \mathrm{cm}^{-3}$, respectively, at $0.2 \mathrm{C}$. These results were ascribed to the high content of NCA (99 wt.\%) while reducing inactive components ( $1 \mathrm{wt} . \% \mathrm{Gr} / \mathrm{PVdF}$ ), which enabled for an enhanced $\rho$ and hence, a large $\mathrm{Q}_{\mathrm{vol}}$ (thinner electrode), as well as a large $Q_{\text {areal }}$ (high mass-loading). 
a

bare

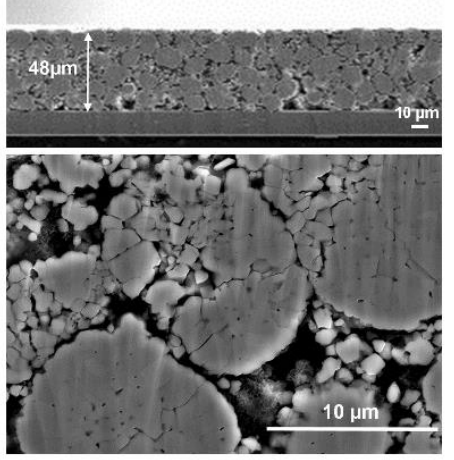

$99: 0.9(\mathrm{Gr}): 0.1 / 19 \mathrm{mg} \mathrm{cm}^{-2} / 3.8 \mathrm{~g} \mathrm{~cm}^{-3}$

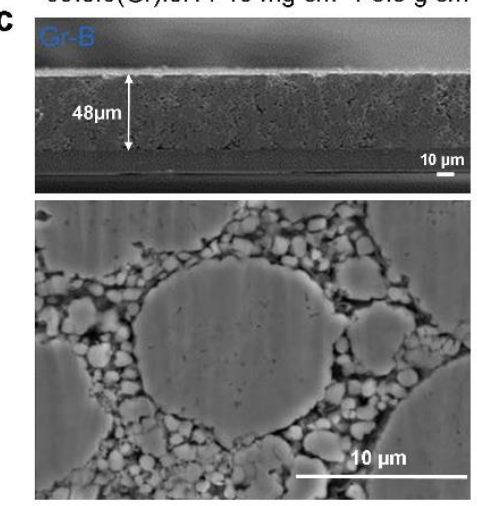

.

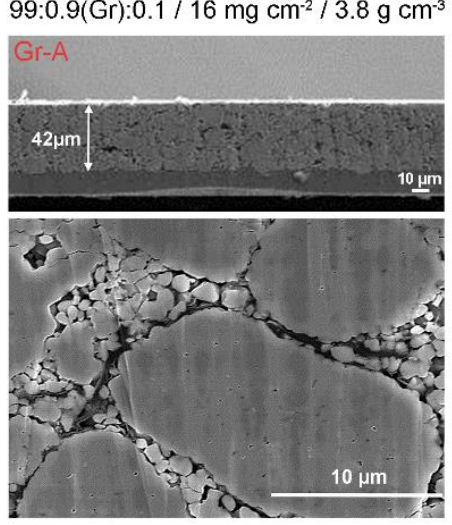

$99: 0.9(\mathrm{Gr}): 0.1 / 19 \mathrm{mg} \mathrm{cm}^{-2} / 3.3 \mathrm{~g} \mathrm{~cm}^{-3}$

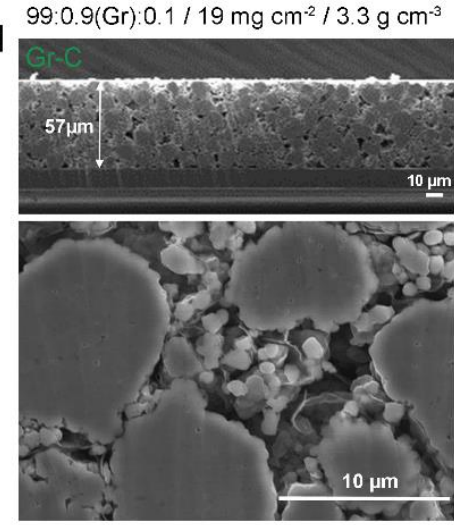

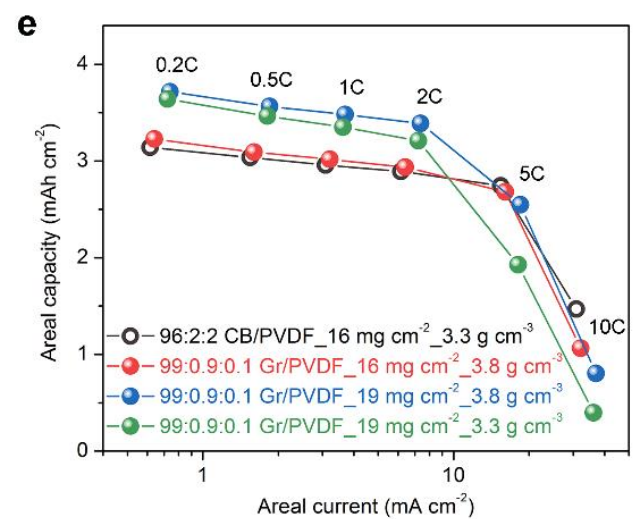

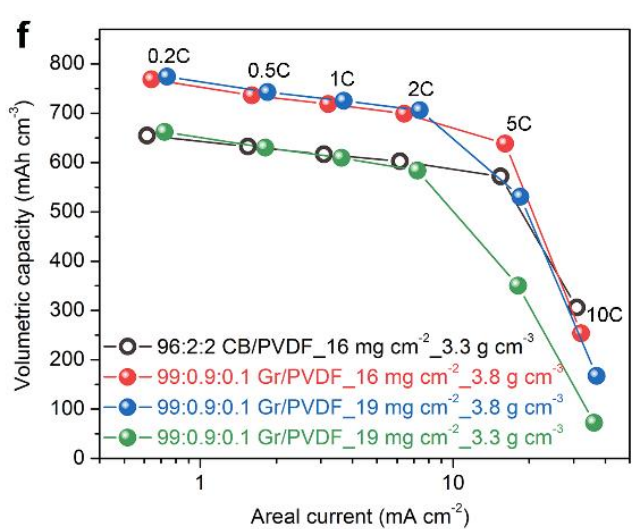

Figure 6. (a-d) Cross-sectional SEM images of CB- or Gr-containing NCA electrodes with different electrode parameters (Ref., Gr-A, Gr-B, and Gr-C) and (e,f) $Q_{\text {areal }}$ and $Q_{\text {vol }}$ with respect to areal current (at 0.2-10 C).

\section{Conclusions}

Electrochemically exfoliated Gr nanosheets were employed as conducting agent in NCA cathodes for LIBs. Gr/PVdF suspensions were fabricated by mixing Gr dispersion (in NMP) and PVdF solution (in NMP) at Gr contents of 10-90 wt.\%. The Gr/PVdF suspensions appeared to be considerably homogeneous, compared to the $\mathrm{CB} / \mathrm{PVdF}$ suspensions. Consequently, the cast Gr/PVdF composite films had uniform microstructures, which was thought to be due to specific interactions between the Gr sheets and PVdF, such as hydrogen bonding and $\pi-\pi$ interactions. By using Gr/PVdF suspensions, we achieved highly packed NCA electrodes featuring a high NCA content of $99 \mathrm{wt} . \%$ and a high $\rho$ of $3.8 \mathrm{~g} \mathrm{~cm}^{-3}$ without notable microcracks. The CP-SEM and AFM-SSRM analyses confirmed that the use of the Gr/PVdF suspension enabled the uniform distribution of Gr nanosheets, ensuring effective conducting pathways within NCA electrodes, even with an extremely small $\mathrm{Gr}$ amount ( $0.9 \mathrm{wt} . \%)$. In addition, the home-made gas cell measurements proved the efficacy of using a small content of Gr/PVdF (1 wt.\%), as compared to the case of conventional CB/PVdF (4 wt. \%), in terms of battery safety. The NCA electrodes using a small content of Gr/PVdF (0.9:0.1, total $1 \mathrm{wt} . \%)$ showed a larger $\mathrm{Q}_{\mathrm{vol}}$ of $\sim 790 \mathrm{mAh} \mathrm{cm}^{-3}$ than that of the Ref. electrode $\left(\mathrm{Q}_{\mathrm{vol}} \sim 610 \mathrm{mAh} \mathrm{cm}^{-3}\right)$ with a commercial-level of electrode setting ( $96 \mathrm{wt} . \% \mathrm{NCA} ; \rho \sim 3.3 \mathrm{~g} \mathrm{~cm}^{-3}$ ) with good capacity retentions during 100 cycles, measured in the voltage ranges of $2.75-4.3 \mathrm{~V}$ and $2.75-4.5 \mathrm{~V} \mathrm{vs}^{-\mathrm{Li}^{+}} / \mathrm{Li}$ and at temperatures of $30^{\circ} \mathrm{C}$ at a current rate of $0.5 \mathrm{C}$. Furthermore, by enhancing the $\mathrm{m}_{\text {areal }}\left(19 \mathrm{mg} \mathrm{cm}^{-2}\right)$ of the $0.9 \mathrm{wt} . \%$ Gr-containing NCA electrode, we demonstrated a high $\mathrm{Q}_{\text {areal }}$ of $\sim 3.7 \mathrm{mAh} \mathrm{cm}^{-2}$ and a high $\mathrm{Q}_{\mathrm{vol}}$ of $\sim 774 \mathrm{mAh} \mathrm{cm}^{-3}$ at $0.2 \mathrm{C}$. These findings suggest that the use of $\mathrm{Gr} / \mathrm{PVdF}$ suspensions is a promising solution for advanced Ni-rich oxide cathodes. 
Supplementary Materials: The following are available online at https://www.mdpi.com/article/10 .3390/ma14092271/s1, Figure S1: AFM data of Gr sheets, Figure S2: XPS C 1s of Gr sheets, Figure S3: Raman data of Gr sheets, Figure S4: Digital photographs of dispersions, Figure S5: Voltage profiles of NCA electrodes, Figure S6: Nyquist plots of NCA electrodes.

Author Contributions: Conceptualization, C.W.P., S.M.H. and Y.-J.K.; methodology, C.W.P., J.-H.L., and W.T.A.R.; investigation, C.W.P., J.-H.L. and W.T.A.R.; validation, C.W.P. and S.M.H.; formal analysis, J.K.S., J.-H.L., W.T.A.R.; writing-original draft preparation, C.W.P.; writing-review and editing, S.M.H., D.W. and Y.-J.K.; supervision, D.W., S.M.H. and Y.-J.K. All authors have read and agreed to the published version of the manuscript.

Funding: This work was supported by a grant from the Korea Evaluation Institute of Industrial Technology (KEIT) (no. 20011905) and a grant from the Korea Institute for Advancement of Technology (KIAT) funded by Ministry of Trade, Industry \& Energy (MOTIE) (no. P0012748).

Institutional Review Board Statement: Not applicable.

Informed Consent Statement: Not applicable.

Data Availability Statement: The data that support the findings of this study are available from the corresponding author upon reasonable request.

Conflicts of Interest: The authors declare no conflict of interest.

\section{References}

1. Cano, Z.P.; Banham, D.; Ye, S.; Hintennach, A.; Lu, J.; Fowler, M.; Chen, Z. Batteries and fuel cells for emerging electric vehicle markets. Nat. Energy 2018, 3, 279-289. [CrossRef]

2. Li, M.; Lu, J.; Chen, Z.; Amine, K. 30 Years of Lithium-Ion Batteries. Adv. Mater. 2018, e1800561. [CrossRef] [PubMed]

3. Lim, B.-B.; Myung, S.-T.; Yoon, C.S.; Sun, Y.-K. Comparative Study of Ni-Rich Layered Cathodes for Rechargeable Lithium Batteries: $\mathrm{Li}[\mathrm{Ni} 0.85 \mathrm{Co} 0.11 \mathrm{Al0} .04] \mathrm{O} 2$ and $\mathrm{Li}[\mathrm{Ni} 0.84 \mathrm{Co} 0.06 \mathrm{Mn} 0.09 \mathrm{Al} 0.01] \mathrm{O} 2$ with Two-Step Full Concentration Gradients. ACS Energy Lett. 2016, 1, 283-289. [CrossRef]

4. Goodenough, J.B.; Kim, Y. Challenges for Rechargeable Li Batteriest. Chem. Mater. 2010, 22, 587-603. [CrossRef]

5. Sun, Y.K.; Myung, S.T.; Park, B.C.; Prakash, J.; Belharouak, I.; Amine, K. High-energy cathode material for long-life and safe lithium batteries. Nat. Mater. 2009, 8, 320-324. [CrossRef] [PubMed]

6. Liu, C.; Li, F.; Ma, L.P.; Cheng, H.M. Advanced materials for energy storage. Adv. Mater. 2010, 22, E28-E62. [CrossRef]

7. Ritchie, A.G. Recent developments and likely advances in lithium rechargeable batteries. J. Power Sour. 2004, 136, 285-289. [CrossRef]

8. Schmuch, R.; Wagner, R.; Hörpel, G.; Placke, T.; Winter, M. Performance and cost of materials for lithium-based rechargeable automotive batteries. Nat. Energy 2018, 3, 267-278. [CrossRef]

9. Wang, Y.; Fu, X.; Zheng, M.; Zhong, W.H.; Cao, G. Strategies for Building Robust Traffic Networks in Advanced Energy Storage Devices: A Focus on Composite Electrodes. Adv. Mater. 2019, 31, e1804204. [CrossRef] [PubMed]

10. Haselrieder, W.; Ivanov, S.; Tran, H.Y.; Theil, S.; Froböse, L.; Westphal, B.; Wohlfahrt-Mehrens, M.; Kwade, A. Influence of formulation method and related processes on structural, electrical and electrochemical properties of LMS/NCA-blend electrodes. Prog. Solid State Chem. 2014, 42, 157-174. [CrossRef]

11. Kraytsberg, A.; Ein-Eli, Y. Conveying Advanced Li-ion Battery Materials into Practice The Impact of Electrode Slurry Preparation Skills. Adv. Energy Mater. 2016, 6, 1600655. [CrossRef]

12. Lee, G.-W.; Ryu, J.H.; Han, W.; Ahn, K.H.; Oh, S.M. Effect of slurry preparation process on electrochemical performances of LiCoO2 composite electrode. J. Power Sour. 2010, 195, 6049-6054. [CrossRef]

13. Bitsch, B.; Dittmann, J.; Schmitt, M.; Scharfer, P.; Schabel, W.; Willenbacher, N. A novel slurry concept for the fabrication of lithium-ion battery electrodes with beneficial properties. J. Power Sour. 2014, 265, 81-90. [CrossRef]

14. Cho, K.Y.; Kwon, Y.I.; Youn, J.R.; Song, Y.S. Evaluation of slurry characteristics for rechargeable lithium-ion batteries. Mater. Res. Bull. 2013, 48, 2922-2926. [CrossRef]

15. Parvez, K.; Li, R.; Reddy Puniredd, S.; Hernandez, Y.; Hinkel, F.; Wang, S.; Feng, X.; Mullen, K. Electrochemically Exfoliated Graphene as Solution-Processable, Highly Conductive Electrodes for Organic Electronics. ACS Nano 2013, 7, 3598-3606. [CrossRef] [PubMed]

16. Parvez, K.; Wu, Z.S.; Li, R.; Liu, X.; Graf, R.; Feng, X.; Mullen, K. Exfoliation of graphite into graphene in aqueous solutions of inorganic salts. J. Am. Chem. Soc. 2014, 136, 6083-6091. [CrossRef] [PubMed]

17. Park, C.W.; Lee, J.-H.; Seo, J.K.; Jo, W.Y.; Whang, D.; Hwang, S.M.; Kim, Y.-J. Graphene collage on Ni-rich layered oxide cathodes for advanced lithium-ion batteries. Nat. Commun. 2021, 12, 2145. [CrossRef] [PubMed]

18. Mattevi, C.; Eda, G.; Agnoli, S.; Miller, S.; Mkhoyan, K.A.; Celik, O.; Mastrogiovanni, D.; Granozzi, G.; Garfunkel, E.; Chhowalla, M. Evolution of Electrical, Chemical, and Structural Properties of Transparent and Conducting Chemically Derived Graphene Thin Films. Adv. Funct. Mater. 2009, 19, 2577-2583. [CrossRef] 
19. López, V.; Sundaram, R.S.; Gómez-Navarro, C.; Olea, D.; Burghard, M.; Gómez-Herrero, J.; Zamora, F.; Kern, K. Chemical Vapor Deposition Repair of Graphene Oxide: A Route to Highly-Conductive Graphene Monolayers. Adv. Mater. 2009, 21, $4683-4686$. [CrossRef]

20. Karan, S.K.; Mandal, D.; Khatua, B.B. Self-powered flexible Fe-doped RGO/PVDF nanocomposite: An excellent material for a piezoelectric energy harvester. Nanoscale 2015, 7, 10655-10666. [CrossRef] [PubMed]

21. Ataur Rahman, M.; Chung, G.-S. Synthesis of PVDF-graphene nanocomposites and their properties. J. Alloy. Compd. 2013, 581, 724-730. [CrossRef]

22. Zhang, X.-J.; Wang, G.-S.; Cao, W.-Q.; Wei, Y.-Z.; Cao, M.-S.; Guo, L. Fabrication of multi-functional PVDF/RGO composites via a simple thermal reduction process and their enhanced electromagnetic wave absorption and dielectric properties. RSC Adv. 2014, 4, 19594-19601. [CrossRef]

23. El Achaby, M.; Arrakhiz, F.Z.; Vaudreuil, S.; Essassi, E.M.; Qaiss, A. Piezoelectric $\beta$-polymorph formation and properties enhancement in graphene oxide-PVDF nanocomposite films. Appl. Surf. Sci. 2012, 258, 7668-7677. [CrossRef]

24. Huang, L.; Lu, C.; Wang, F.; Wang, L. Preparation of PVDF/graphene ferroelectric composite films by in situ reduction with hydrobromic acids and their properties. Rsc Adv. 2014, 4, 45220-45229. [CrossRef]

25. Xu, X.-L.; Yang, C.-J.; Yang, J.-H.; Huang, T.; Zhang, N.; Wang, Y.; Zhou, Z.-W. Excellent dielectric properties of poly(vinylidene fluoride) composites based on partially reduced graphene oxide. Compos. Part B Eng. 2017, 109, 91-100. [CrossRef]

26. Han, J.; Li, H.; Kong, D.; Zhang, C.; Tao, Y.; Li, H.; Yang, Q.-H.; Chen, L. Realizing High Volumetric Lithium Storage by Compact and Mechanically Stable Anode Designs. ACS Energy Lett. 2020, 5, 1986-1995. [CrossRef]

27. Zhang, C.; Lv, W.; Tao, Y.; Yang, Q.-H. Towards superior volumetric performance: Design and preparation of novel carbon materials for energy storage. Energy Environ. Sci. 2015, 8, 1390-1403. [CrossRef]

28. Gaberscek, M.; Moskon, J.; Erjavec, B.; Dominko, R.; Jamnik, J. The Importance of Interphase Contacts in Li Ion Electrodes: The Meaning of the High-Frequency Impedance Arc. Electrochem. Solid State Lett. 2008, 11, A170. [CrossRef]

29. Thorat, I.V.; Joshi, T.; Zaghib, K.; Harb, J.N.; Wheeler, D.R. Understanding Rate-Limiting Mechanisms in LiFePO4 Cathodes for Li-Ion Batteries. J. Electrochem. Soc. 2011, 158, A1185-A1193. [CrossRef]

30. Hwang, S.M.; Lim, Y.-G.; Kim, J.-G.; Heo, Y.-U.; Lim, J.H.; Yamauchi, Y.; Park, M.-S.; Kim, Y.-J.; Dou, S.X.; Kim, J.H. A case study on fibrous porous $\mathrm{SnO} 2$ anode for robust, high-capacity lithium-ion batteries. Nano Energy 2014, 10, 53-62. [CrossRef]

31. Li, W.; Erickson, E.M.; Manthiram, A. High-nickel layered oxide cathodes for lithium-based automotive batteries. Nat. Energy 2020, 5, 26-34. [CrossRef]

32. Myung, S.-T.; Maglia, F.; Park, K.-J.; Yoon, C.S.; Lamp, P.; Kim, S.-J.; Sun, Y.-K. Nickel-Rich Layered Cathode Materials for Automotive Lithium-Ion Batteries: Achievements and Perspectives. ACS Energy Lett. 2016, 2, 196-223. [CrossRef]

33. Bak, S.-M.; Nam, K.-W.; Chang, W.; Yu, X.; Hu, E.; Hwang, S.; Stach, E.A.; Kim, K.-B.; Chung, K.Y.; Yang, X.-Q. Correlating Structural Changes and Gas Evolution during the Thermal Decomposition of Charged LixNi0.8Co0.15Al0.05O2 Cathode Materials. Chem. Mater. 2013, 25, 337-351. [CrossRef]

34. Kim, J.; Lee, H.; Cha, H.; Yoon, M.; Park, M.; Cho, J. Prospect and Reality of Ni-Rich Cathode for Commercialization. Adv. Energy Mater. 2018, 8, 1702028. [CrossRef]

35. Park, K.Y.; Lim, J.M.; Luu, N.S.; Downing, J.R.; Wallace, S.G.; Chaney, L.E.; Yoo, H.; Hyun, W.J.; Kim, H.U.; Hersam, M.C. Concurrently Approaching Volumetric and Specific Capacity Limits of Lithium Battery Cathodes via Conformal Pickering Emulsion Graphene Coatings. Adv. Energy Mater. 2020, 10, 2001216. [CrossRef] 